\title{
Second Language Acquisition Feature Exploration based on Affordance Theory
}

\author{
Yan Sun
}

School of Foreign Languages, Guangdong Pharmaceutical University, Guangzhou, 510006, China Keywords: Affordance theory; Second language acquisition. Characteristics

\begin{abstract}
Affordance theory initially reveals the interaction between biology and environment. With the development of second language acquisition, it is constantly applied to second language acquisition. In language learning, learners acquire knowledge and language according to their own needs. From the perspective of affordance theory, the paper discusses the relationship between the local environments perceived in second language acquisition to help students understand affordance, and in the process of language learning, improve teaching quality effectively.

Second language acquisition refers to that learners master one or more languages except for their native language. Second language acquisition began to be studied from the seventy s of the 20th century western gradually. With the deepening of the research, second language acquisition research fuses with other disciplines gradually and is widely absorbed into system study, so as to realize the innovation of second language acquisition research and development. Researchers in second language acquisition mostly study second language acquisition learning process from the perspectives of social science and psychological science, and the main purpose is to understand how learners better master another language after learning English language, and master the characterization of language learning.
\end{abstract}

\section{AfFORdanCE}

Affordance theory is a cross discipline, which is closely related to ecological psychology, perception psychology and other disciplines. Affordance is an important concept of psychology. People extract affordance from surroundings in man's cognitive process, and the basic characteristic of affordance theory is from ecology point of view; explore the relationship between biology and environment, and in the special relationship with the environment in the process of biological evolution and development. Psychologist Thomas Ronald Reagan gave affordance three definitions: one is that affordance is a potential possibility; two is that affordance is body characteristic in the environmental system; three is that the extract of affordance information is restricted by intention. Thus we can study the characteristics of the second language acquisition from the perspective of affordance.

\section{PSYCHOLOGICAL AND LINGUISTIC REPRESENTATIONS OF SECOND LANGUAGE ACQUISITION LEARNERS}

A. The mental representation of second language acquisition learners

The mental representation of second language acquisition learners refers to the brain storing information way, which is also a kind of memory state, mainly researches that if the brain completely copies the exact words while accepting outside information, or just the memory of the meaning of a sentence. John Robert Anderson did a research about second language acquisition learners' mental representation. The experiment shows four sentences. Let the listener listen to four sentences. The study found that when the listener just heard the first sentence, they used the first sentence as a guide, and found the same sentences in the manual below. Before experiments, the listeners were informed the order of the sentences. The study found that all the listeners were able to clearly distinguish the deep meaning of the sentences, and found the same meaning sentence as the guide words, but only half of the test listeners can distinguish the differences between sentences and words form. Experiments have proved that language information storage did not rely on sentences or words. In psychology, thesis is an important research concept, which mainly refers to the smallest unit's performance between declarative knowledge. The smallest unit is the smallest unit of word meaning expression. Psychological prophet shows that we integrate the semantic meaning of the sentence in in the process of sentences memory repeatedly. In memory deep decoding, proposition form surface coding in sentences and words to deepen the memory of the sentence. 
The mental representation of second language acquisition mainly refers to the second language accept awareness and understanding through receptor, and form a common form in brain nerve and mental models. So the mental representation of second language acquisition can be explored by retelling training in college English teaching. In college English teaching, teachers often use the method of encouragement to let the students to retell reading or hearing materials. Students can use different sentences and words to express the original meaning and content of raw materials in the learning process. While in the process of retelling, there will be some mistakes in grammar. So you can see from here that second language materials acquires deep coding, and extracts the surface layer coding. At the time of second language acquisition learners try to output sentences, often output language sentences correct expression and purpose are not consistent, so in essence, the mental representation of second language acquisition and language learning are the same, and its working principles are to set up deep encoding based on surface layer coding, and then extract the surface encoding from the deep encoding for the expression of specific language.

$B$. The language characterization of second language acquisition

Language characterization mainly contains single concept words and complex concept sentences. The speakers convey thoughts through language expression, and are the mental representation. That is to say people activated the mental representation in brain by the objective internalization of the reality. Therefore language representation and mental representation are two-way. Language representation can reflect and activate mental representation, and mental representation also determines linguistic representations of people. But language representation can never go beyond the differences between languages. Such as English and Chinese have larger difference in aspects as pronunciation, vocabulary and usage, namely the existence of these differences make the language representation to be converted into psychological representation which becomes very complicated. Psychological linguists think that humans acquire language is mainly composed of two parts, one is form, the other is semantic, and the two forms are stored in people's memory for representation. Two levels of language representation are independent and connect each other, and form language representation through statement and sentence patterns, etc. The semantic representation of language shows concept, category and proposition. So the main difference between mother tongue study and second language acquisition is that children realize vocabulary learning mainly in two levels: word name and concept layer. At the time of acquisition of mother tongue, they cannot only grasp the meaning of words, will also be able to master the words and properties of other aspects. In the process of learning language, they cannot only get words semantic meaning, but words spelling and pronunciation. While studying second language acquisition, learners only master the form features, such as pronunciation and spelling words, and often rely on the native language vocabulary system in meaning understanding, thus seriously neglect the word semantic cues in language acquisition process in the context. Coupled with learners are not in target language countries, lack language culture input. Without rich language stimulation, therefore in the process of learning, it is difficult to master all the meanings of a word. So in the teaching of second language acquisition, we should pay attention to language output and input, guide students from the perspective of affordance theory for language learning opportunities and the environment.

\section{SECOND LANGUAGE ACQUISITION TEACHING ANALYSIS IN VIEW OF AFFORDANCE THEORY}

Affordance is mainly the interaction and relationship between learners and the environment from the perspective of ecological linguistics. Affordance theory plays an important role in language learning, and can help learners to build mobile vision, establishes a kind of inner link with the surrounding environment, produces the opportunity and environment to learn. Affordance links up the learners and the surrounding environment. Learners can only build sensory perception of learning activity in complex environment, and analyze the thinking. So for affordance characteristics in language environment, teachers in language teaching should pay attention to several aspects:

A. Design a subject language learning environment

Affordance has a certain relation to the perceivable activities environment, and foreign language 
teaching is one of the classroom teaching environments. Foreign language teaching classroom can provide learners with language learning environment and the opportunity to provide students with language learning material and temporary activity level, and, more importantly, language learning classroom can provide affordance to help students participate in language learning activities. So in the teaching of second language acquisition, first of all, give students enough language learning environments, understand different requirements and characteristics of language learners, and according to the students' needs, in the classroom teaching, provide for students different teaching materials and multimedia equipment support. Learners can form an interactive relationship with learning environment through the perception of learning materials. In the process of teacher's teaching, understand learners' perception ability. If the teacher does not understand affordance in teaching environment thoroughly, it will seriously affect the effect of language learning.

\section{$B$. Highlight the interaction between learners and the environment}

The interaction between language learners and environment includes classroom learning environment interaction and social language learning environment interaction, so teachers in teaching should pay attention to these two aspects of interaction. Language learning need not only learners' interaction in classroom environment, also need interaction in social environment, and language learning cultural background is also very important for language learners. Therefore, language learning cannot leave interaction with social environment. Linguists Harry Yanei thinks that classroom environment itself is greatly social. Language classroom learning can show that in the process of teaching, research and study, students' practical context provides students with many social and linguistic approaches, and provides many social and linguistic affordances for students. Learners through frequent use of affordance will soon understand that affordance is not only a language learning tool, but the founder of language learning context, and it exists as a medium.

C. Ensure that every language learner has enough opportunity to learn

From the perspective of ecology, second language acquisition mainly studies the relationship between human in the process of language learning and language system, and this kind relation does not exist in isolation, but in the wide consciousness of students, and in their own perception and attitude towards the environment. So teachers should consider the differences of different learners' perception on the surrounding and education environment, and consider the existing differences between individuals which lead to students larger study effect differences when learning a language. So students in the same learning environment have different learning perception, although the amount of assignments and learning are the same in language learning. Positive and concentrate learners can more aware of the available language learning environment. So teachers in teaching should lead students enter the classroom teaching, help students understand different language environment, learn to perceive language learning environment so as to improve the effectiveness of their language learning.

\section{Pay attention to language input and output}

Second language learners first contact purpose language materials are input, and this is an important condition for second language learners to learn. The output can efficiently help second language learners in learning the language to carry on deep processing. So in teaching, the teacher should create a favorable environment and its context for the purpose language output and input. Use multimedia equipment or original English movies and so on to give students a lot of understandable language input, help students create more opportunities for language learning for more efficiency in learning a foreign language.

\section{E. Guide students be concept-centered}

Based on the mental representation and language characterization of second language learners, in the teaching of vocabulary, pay attention to guide students understand the concepts, have right attitude towards second language vocabulary's Chinese explanation, let students grasp correct pronunciation and vocabulary spelling, and on the basis of understanding sentence and semantic differences between Chinese and western culture, prevent students' second language vocabulary abuse in language learning, which may influence the effect of second language learning. 


\section{IV.CONCLUSION}

Based on the theory of affordance, according to the students psychological and linguistic representation of second language learning, guide students in perception of the education environment and the language learning opportunities according to their own understanding, construct classroom language learning environment, form students in-classroom environment interaction state, and really realize second language learning.

\section{REFERENCES}

[1] Du Jia. Second language acquisition research based on affordance [J]. Journal of Social Sciences in Nanjing, 2011, (03) : 133-137.

[2] $\mathrm{Wu}$ Wen. Social and cultural theory and ecology language teaching [J]. Journal of Tianjin Foreign Studies University, 2011, (3) : 54-61.

[3] Wu Wen, Li Sen. Ecological language teaching under the view of social culture [J]. Journal of Shandong Foreign Language Teaching, 2009, (6) : 48-53.

[4] Li Rui. Culture input in foreign language teaching from ecological language teaching view[J]. Journal of Heilongjiang Institute of Education, 2012, (11) : 87-89.

[5] Wen Jia, ZhangJing. English teaching exploration in ecological mode [J]. Forest Teaching, 2015, (8) : 34 and 35. 